\title{
Couple Relationship Education: A Randomized Controlled Trial of Professional Contact and Self-Directed Tools
}

\author{
Martina Zemp and Corina A. Merz \\ University of Zurich \\ W. Kim Halford \\ University of Queensland
}

\author{
Fridtjof W. Nussbeck \\ Bielefeld University \\ Marcel Schaer Gmelch \\ Zurich University of Applied Sciences
}

Guy Bodenmann
University of Zurich

\begin{abstract}
The aim of this randomized controlled trial was to examine the efficacy of an evidence-based relationship distress prevention program, the Couples Coping Enhancement Training (CCET), in dual well-earning couples and to investigate whether effects vary by (a) hours of professional contact and (b) mode of delivery (face to face vs. self-learning DVD). $N=159$ couples were randomly assigned to 1 of 4 intervention conditions: (1) standard CCET (15 hours face to face), (2) compact CCET (12 hr face to face), (3) short CCET (self-learning DVD $+8 \mathrm{hr}$ face to face), or (4) wait-list control group. Relationship satisfaction and dyadic coping skills were assessed by means of questionnaires completed prior to and 2 weeks after completion of the treatment, at 3-month follow-up, and at 6-month follow-up. Baseline latent change models for 2 factors showed that the CCET enhanced relationship satisfaction and dyadic coping skills in couples relative to the wait-list control group, albeit effects were small. The standard format of the CCET was not more effective than the compact or the short format indicating that reduced amount of professional contact did not decrease the treatment's efficacy and that the self-learning DVD successfully replaced the psycho-educational part of the program. Since dual earner couples usually face multiple stressors, it is a promising finding that they can strengthen their relationship with a relatively short time investment.
\end{abstract}

Keywords: couple relationship education, Couples Coping Enhancement Training, intimate relationship, stress, self-directed learning

The significance of prevention programs for couples (collectively referred to as Couple Relationship Education, or CRE) to prevent relationship distress has repeatedly been shown (Halford, 2001). However, CRE evaluation studies differ substantially in terms of effect sizes (Halford \& Bodenmann, 2013; Hawkins, Blanchard, Baldwin, \& Fawcett, 2008). As a consequence, scholars have successfully begun to examine the factors which moderate

Martina Zemp and Corina A. Merz, Department of Psychology, University of Zurich; Fridtjof W. Nussbeck, Department of Psychology, Bielefeld University; W. Kim Halford, School of Psychology, University of Queensland; Marcel Schaer Gmelch, School of Applied Psychology, Zurich University of Applied Sciences; Guy Bodenmann, Department of Psychology, University of Zurich.

Some ideas or data from this article have been presented at the 11th European Academy of Occupational Health Psychology Conference and at the 42nd annual European Association of Behavioral and Cognitive Therapies.

Correspondence concerning this article should be addressed to Martina Zemp, who is now at Department of Psychology, University of Mannheim, L13, 15-17, 68131 Mannheim, Germany. E-mail: m.zemp@psychologie .uni-mannheim.de the efficacy of CRE (e.g., Hawkins, Stanley, Blanchard, \& Albright, 2012). For instance, two potential moderators in this context are (a) the amount of professional contact (e.g., Hawkins et al., 2008) and (b) the mode of delivery, that is, face-to-face versus self-learning material (e.g., McAllister, Duncan, \& Hawkins, 2012). The goal of this randomized controlled trial (RCT) was to examine whether these two factors affect the efficacy of an evidence-based relationship distress prevention program (the Couples Coping Enhancement Training CCET; Bodenmann \& Shantinath, 2004) in Swiss dual well-earning couples.

\section{Effects of Professional Contact and Mode of Delivery in CRE}

CRE programs vary widely in terms of hours of interaction between participants and providers. Hawkins et al. (2008) classified CRE into low-dosage (1-8 hr), moderate-dosage (9-20 hr), and high-dosage programs $(21+\mathrm{hr})$. They found that moderatedosage CRE had larger effect sizes than low-dosage CRE, but there was no additional advantage with high-dosage programs. However, as this was a meta-analysis, the factor dosage was confounded with other factors, for example, with the content of the treatment itself. Hence, it is important to directly investigate dos- 
age effects within a single study where couples are randomly assigned to the same treatment, which only differ in terms of hours of professional contact, but not in content or rationale of the intervention. In this study, we focused on varying hours of professional contact within the moderate-dosage of 9 to $20 \mathrm{hr}$ defined by Hawkins and colleagues (2008), because this level of dosage yielded highest cost-effectiveness. For this purpose, we compared a 15-hr face-to-face workshop (the standard CCET: 2 days at the weekend) to a 12-hr face-to-face workshop version (the compact CCET: one evening and one day at the weekend). Even this small difference in hours of professional contact is of practical relevance, for example, in terms of intervention's cost, time restrictions for the couple, and need for child care/babysitting and so forth.

Another important factor known to influence the efficacy of CRE programs is the mode of delivery, that is, face to face by a provider versus self-directed tools, such as an interactive DVD as it is used in this study. Self-directed learning materials have several advantages over traditional formats (e.g., Duncan, Steed, \& Needham, 2009; Halford, Moore, Wilson, Farrugia, \& Dyer, 2004): (a) They can reduce the required hours of professional (face to face) contact, and thus costs, by allowing couples to complete at least parts of the program at home. (b) They enhance the users' privacy, anonymity, and flexibility. (c) They can be accomplished in the personal environment and private setting at any time. (d) They are delivered and elaborated individually; hence, couples are free to work on aspects of the training which are of most interest for them. In this way, self-directed CRE may successfully mitigate couples' perceived obstacles to attendance (e.g., high monetary cost and time commitment, low privacy), thereby extending the potential reach of CRE (Braithwaite \& Fincham, 2007; Wilson \& Halford, 2008). On the downside, approaches that are purely self-directed might have some disadvantages, for instance, lack of individualized and personal support and decreasing motivation and engagement of participants, leading to a relatively high level of attrition (e.g., Braithwaite \& Fincham, 2009, 2011). These are the reasons why self-directed relationship education is often combined with face-to-face components (i.e., blended programs) to strengthen their impact. Blended programs are increasingly used in the context of CRE and evidence is accumulating that they are more effective in enhancing the couples' intimate relationship compared to either face-to-face or self-directed programs alone (Halford et al., 2010; McAllister et al., 2012). In the current study, we want to add to this knowledge by comparing the standard and compact format of the CCET (face to face only) to the (blended) short CCET (self-learning DVD $+8 \mathrm{hr}$ face to face). The applied DVD (Bodenmann, Schaer, \& Gmelch, 2008) has been evaluated previously with results indicating its efficacy (Bodenmann, Hilpert, Nussbeck, \& Bradbury, 2014).

\section{CRE in Dual Well-Earning Couples}

Previous CRE efficacy studies have explored whether specific target populations benefit differently from CRE but most of them focused on at-risk couples (Halford, Sanders, \& Behrens, 2001; Petch, Halford, Creedy, \& Gamble, 2012). In contrast, only little headway has been made to systematically examine the efficacy of CRE in relatively high functioning couples. Swiss dual-earner couples (herein referred to as "dual well-earning couples"), where both partners work by their own choice rather than for financial reasons, generally enjoy certain privileges and high resources. The majority of them have a high standard of life, above-average income and status, and high self-realization. They often hold a fulfilling job or a successful career and probably enriching relationships with their colleagues at work. On the other side, however, when both partners work, couples usually face lack of time and high everyday work stress, entailing the risk of spillover into the intimate relationship (Matthews, Del Priore, Acitelli, \& Barnes-Farrell, 2006). Work and intimate relationships are central life domains (Frone, Russell, \& Cooper, 1992) that become increasingly interconnected due to the growing number of dualearner couples and the impact of technology in blurring work and home roles (Edwards \& Rothbard, 2000). Research findings suggest a reciprocal spillover of stress between work and intimate relationships. Specifically, negative mood associated with stress at work is often carried home at the end of the day (Ilies et al., 2007), and work stress is associated with perceived couple relationship problems, withdrawal and angry-hostile interaction with one's partner (e.g., Neff \& Karney, 2004; Schulz, Cowan, Cowan, \& Brennan, 2004; Story \& Repetti, 2006). Conversely, relationship stress may spill over to work and is associated with low job satisfaction and performance, and high risk for job burnout (Peeters, Montgomery, Bakker, \& Schaufeli, 2005). By the same token, when the interconnection of work and relationship is well managed, both domains can positively affect each other. For instance, positive experiences in the intimate relationship are associated with better work performance (Sonnentag, 2003), and vice versa (Greenhaus \& Powell, 2006).

Against this backdrop, the study of prevention-oriented CRE in dual well-earning couples is important in order to untangle whether CRE can prevent relationship distress or declines in relationship satisfaction due to high level of daily stress stemming from balancing work and family life demands. Moreover, given that dual earner couples deal with multiple everyday stressors and lack of time, blended CRE programs potentially reach a larger population to the extent that they require less time and allow more flexible use in comparison to traditional workshop formats (Halford et al., 2004; McAllister et al., 2012). Dual-earner couples might prefer a more convenient approach, and tailor learning opportunities and tools that are available at any time and from any place. It is thus conceivable that they may particularly benefit from blended CRE programs. Therefore, dual well-earning couples are the target group of the present study (that is, both partners had to work a minimum of $18 \mathrm{hr}$ per week by their own choice).

\section{The Stress-Buffering Role of Dyadic Coping}

One important resource to prevent negative stress spillover and to strengthen a positive interconnection between work and home is dyadic coping (Revenson, Kayser, \& Bodenmann, 2005). Dyadic coping is defined as the way partners communicate perceived stress to each other, support each other in times of stress, and deal jointly with daily stressors within the couple as a unit (Bodenmann, 1995). Dyadic coping buffers the negative effects of stress on both partners' relationship satisfaction (Brock \& Lawrence, 2008; Falconier \& Epstein, 2011), as well as on the quality of the partners' interaction (Bodenmann, Meuwly, Bradbury, Gmelch, \& Ledermann, 2010). Given that dyadic coping appears to play a major role in alleviating the 
detrimental effects of stress and that it is a powerful predictor of relationship satisfaction (Falconier, Jackson, Hilpert, \& Bodenmann, 2015), interventions that enhance dyadic coping could help couples foster their relationship quality.

The Couples Coping Enhancement Training (CCET; Bodenmann \& Shantinath, 2004) is among the first couple relationship education (CRE) programs that go beyond teaching constructive communication in partners; it also addresses the enhancement of dyadic skills to cope with stress. The efficacy of the program has been repeatedly supported (e.g., Ledermann, Bodenmann, \& Cina, 2007), but no prior study, to our knowledge, has evaluated the efficacy of CCET in dual well-earning couples to date. In the current study, three key components of dyadic coping were assessed and separately examined as outcome variables: (a) own stress communication (how Partner A tells Partner B about his or her own stress and vice versa), (b) the partner's dyadic coping (how Partner B supports Partner A in dealing with the stress and vice versa), and (c) evaluation of dyadic coping (how Partner A or B perceives the quality of the other's support). Besides dyadic coping skills, relationship satisfaction was evaluated as an outcome variable in this trial since previous meta-analytic research has found that skills measures usually produce larger effect sizes than relationship satisfaction (Hawkins et al., 2008). Thus, to adopt a more rigorous test, relationship satisfaction should also be reported in evaluation studies of CRE.

\section{The Current Study}

In summary, CRE efficacy seems to vary by (a) hours of direct interaction between provider and participant couples and (b) mode of delivery. In this study we examined the impact of these two factors on the effects of the Couples Coping Enhancement Training (CCET) on relationship satisfaction and dyadic coping skills in 159 dual well-earning couples who were randomly assigned to one of four intervention conditions: (1) the standard CCET (15 hr face to face), (2) the compact CCET (12 hr face to face), (3) the short CCET (approximately $3-4 \mathrm{hr}$ self-learning DVD $+8 \mathrm{hr}$ face to face), or (4) a wait-list control group. Importantly, only the psychoeducational part was shortened from the standard format to attain the adapted formats and, beyond, psychoeducation was delivered by a DVD in the short format. Behavioral trainings and exercises were face to face, analogous to the standard format. Thus, the short CCET and the compact CCET differ mainly in the way psychoeducation was provided (via DVD or face to face by a provider).

First, we tested whether CCET generally increased the couples' relationship satisfaction and dyadic coping when comparing the intervention groups with the wait-list control group. Second, we investigated the comparability of the efficacy between the different CCET formats. That is, we tested the effects of hours of professional contact on the treatment efficacy comparing the standard CCET to the compact CCET (i.e., 15 vs. $12 \mathrm{hr}$ face to face). We also examined the treatment efficacy in terms of mode of delivery comparing the compact CCET to the short CCET (12 hr face to face vs. self-learning DVD $+8 \mathrm{hr}$ face to face). Furthermore, we investigated whether the combination of hours of professional contact and mode of delivery influenced the efficacy ( $15 \mathrm{hr}$ face to face vs. self-learning DVD $+8 \mathrm{hr}$ face to face).
Method

\section{Participants}

The participants constituted a universal prevention sample of 159 Swiss heterosexual dual well-earning couples. They were recruited in newspaper articles and in online forums discussing work-family related topics. Inclusion criteria for participation were a good knowledge of German, being in a committed relationship for at least 1 year, and both partners working a minimum of $18 \mathrm{hr}$ per week by their own choice (not for financial reasons). Interested couples could sign up for the study online and meeting of the inclusion criteria was checked thoroughly by a subsequent telephone screening through a clinical psychologist. The psychologist asked the couples in the telephone screening about their current intimate relationship (i.e., whether they or their partner report any form of elevated distress in the relationship and whether they are or have ever been in individual or couple therapy due to relationship problems with the current partner). Couples reporting severe relationship problems or being/having been in therapy were excluded from participation since the study treatments were preventive in nature. In total, 199 couples were interested in the study; out of these, 168 couples met the inclusion criteria. Couples who withdrew from the study prior to the training, who did not finish the full training, or who showed low compliance (e.g., refusing to participate in supervised exercises during the training) were excluded from data analysis. Thus, the final dataset for the current analyses contained 159 couples. Couples' allocation to the study groups and their flow through the study is depicted in Figure 1.

Mean age was 40.14 years $(S D=7.80)$ in women and 42.35 years in men $(S D=8.29)$, respectively. Relationship duration ranged from 2 to 40 years $(M=13.24$ years, $S D=8.09)$. Ninety-two percent of the couples were married. The highest level of women's education included mandatory school years (3\%), apprenticeship (16\%), high school (8\%), and bachelor's degree or higher (73\%). Among men, the highest level of education included mandatory school years (5\%), apprenticeship (16\%), high school $(7 \%)$, and bachelor's degree or higher $(72 \%)$. Workload of participants were relatively high; the average time spent at work for women was $39.69 \mathrm{hr}(S D=17.34)$ per week (full-time employment in Switzerland contains $42 \mathrm{hr}$ per week). For men, the average workload per week was $50.54 \mathrm{hr}(S D=17.57)$. The yearly net income of women was for 35\% less than 61,220 USD ( $<60,000 \mathrm{CHF}$ ); for $45 \%$ between 61,220 and 122,442 USD (61,000 and 120,000 CHF); and 20\% had a higher income. Among men, $9 \%$ earned less than $61,220 \mathrm{USD}(<60,000 \mathrm{CHF})$ per year; $46 \%$ between 61,220 and 122,442 USD $(61,000$ and 120,000 $\mathrm{CHF}$ ); and $45 \%$ had a higher income. With respect to these variables, participants represent Swiss upper-income dual-earner couples. No significant differences were found in demographic characteristics between the study groups.

\section{Procedure}

Eligible couples were randomly assigned to one of the four study conditions ( $n=39$ to standard CCET, $n=39$ to compact CCET, $n=40$ to short CCET, and $n=41$ to the wait-list control group; see Figure 1). Block randomization was used to implement the random assignment to conditions in order to ensure an equal 


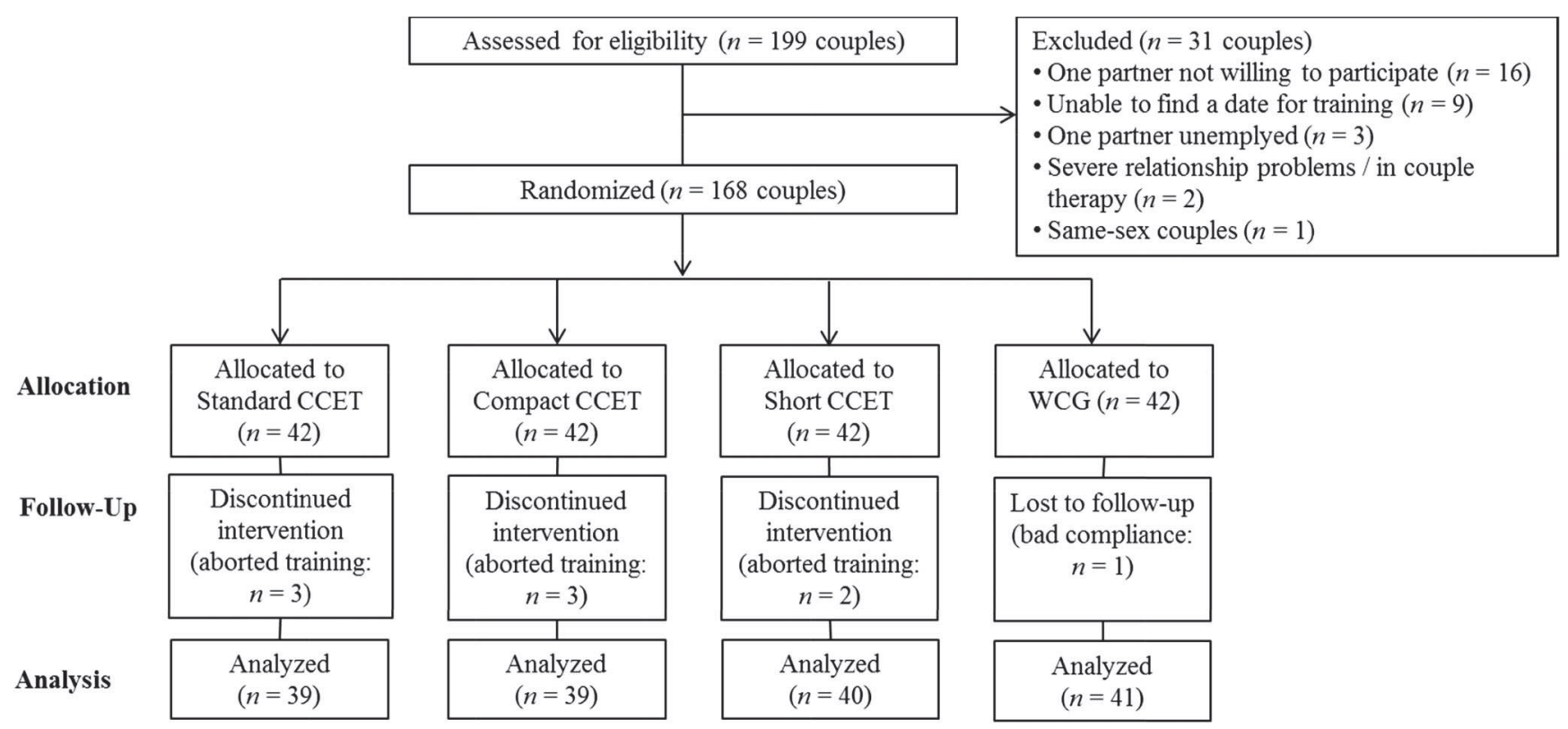

Figure 1. Couples' allocation to study groups and their flow through the study. CCET $=$ Couples Coping Enhancement Training; WCG $=$ wait-list control group.

allocation to the study groups. There were two ways of randomization depending on how the couples registered for study participation: They were either randomly assigned to one of the four groups automatically by a computer algorithm when they followed the link posted in online forums, or by a person of the study administration in case where couples registered by e-mail or telephone. Participants were asked to complete a set of questionnaires online at four times: at preassessment (T1: 2 weeks prior to the treatment), at postassessment (T2: 2 weeks after completion of the treatment), at 3-month follow-up (T3), and at 6-month follow-up (T4). Time intervals between questionnaires were the same for the wait-list control group. All intervention couples received the CCET for the same price, that is, for one third of the original costs of the standard format as an incentive, that is, 290 CHF (293 USD approximately).

\section{Treatments}

Standard CCET. The Couples Coping Enhancement Training (CCET) is an evidence-based cognitive-behavioral relationship distress prevention program (Bodenmann \& Shantinath, 2004). In addition to the enhancement of constructive communication and problem-solving skills, CCET also addresses the couple's dyadic skills to cope with stress. Several didactic elements are used in this training: short lectures with video examples, diagnostic assessments, video and live demonstrations by the workshop providers that model effective communication and dyadic coping skills, and supervision and feedback on the couple's behaviors in exercises according to a ratio of one trainer per two couples.

The standard format of the CCET is offered as a 15-hr face-toface workshop ( 2 days at the weekend) in a group setting of 4-8 couples. Providers in the CCET group were accredited (advanced level graduate students in clinical psychology) who had received
$30 \mathrm{hr}$ of training over a 4-day period and $20 \mathrm{hr}$ of group supervision. Each provider had successfully passed a written exam and an evaluation of a videotaped couple coaching (licensing) before delivering the program.

Compact CCET. The standard format of the CCET was adapted into a compact format of a 12-hr face-to-face workshop (one evening and one day at the weekend). Participants attended a group session introducing the key ideas, theoretical background, and psychoeducation of the CCET on one evening run by one provider. On the following whole day, the focus was on supervised skills training on skills introduced the evening before (communication, problem solving, dyadic coping). Only the educational part (first evening) was shortened from the standard format to attain a compact format. Hence, there is less psychoeducation and theory in this format compared to the standard CCET. Training, supervision, and feedback on the couples' behaviors in exercises were held analogously to the standard format. Program providers were equally trained and we, thus, assume that there were no differences with regard to the quality of delivering the skills training that might have influenced the treatment effects. A high degree of standardization was achieved by means of a detailed and highly structured manual and close supervision of the trainers similar to the standard program.

Short CCET. The short format of the CCET contains a psychoeducational self-learning DVD (Bodenmann et al., 2008) plus $8 \mathrm{hr}$ face-to-face training on one single day. Prior findings supported that the CCET-DVD is effective in enhancing dyadic coping skills (Bodenmann et al., 2014). Participants received the DVD 2 weeks before participating in the 8-hr training. The DVD introduced key ideas and theoretical background of the CCET, thus largely replacing the group session on the first evening of the compact CCET format (psychoeducational part). Hence, the short CCET and the compact CCET differ mainly in the way psychoe- 
ducation was provided, that is, face to face by a provider in the compact CCET and via DVD in the short CCET. By this means, the short CCET required fewer hours of interaction between participants and providers (only $8 \mathrm{hr}$ ) than the standard format ( $15 \mathrm{hr}$ ) and the compact format (12 hr). Reported mean watching of DVD was $M=3.68 \mathrm{hr}(S D=2.00)$ in women, and $M=3.45 \mathrm{hr}(S D=$ 1.90 ) in men, respectively. Again, providers of the skills training were equally trained to ensure standardization and a similar quality of delivering the programs through the treatment formats.

\section{Measures}

Dyadic coping. Three subscales of the Dyadic Coping Inventory (DCI; Bodenmann, 2008) were used to assess dyadic coping skills: (a) own stress communication (i.e., how Partner A tells Partner B about his or her own stress), (b) the partner's dyadic coping (i.e., how Partner A perceives that Partner B tells Partner A about his or her own stress and how Partner B supports Partner A in dealing with the stress), and (c) evaluation of dyadic coping (how both partners perceive the quality of the partner's support). The subscale "own stress communication" was measured with four items (e.g., I tell my partner openly how I feel and that I would appreciate his or her support). Cronbach's alpha for women was between $\alpha=.79$ and $\alpha=.85$, and for men between $\alpha=.74$ and $\alpha=.81$ over all assessments. The subscale "partner's dyadic coping" represents one partner's perceptions of the other partner's stress communication (e.g., My partner tells me openly how she/he feels and that she/he would appreciate my support) and the other partner's support and coping (e.g., My partner expresses that she/he is on my side). Cronbach's alpha for women was between $\alpha=.89$ and $\alpha=.92$, and for men between $\alpha=.86$ and $\alpha=.90$ over all assessments. The subscale "evaluation of dyadic coping" was assessed with two items (e.g., I am satisfied with the support $I$ receive from my partner and the way we deal with stress together). Cronbach's alpha for women was between $\alpha=.83$ and $\alpha=.95$, and for men between $\alpha=.84$ and $\alpha=.91$ over all assessments. Response options for each item ranged on a 5-point Likert scale from rarely (1) to very often (5). The psychometric properties of the DCI have been examined in a large validation study with 2,399 participants (Bodenmann, 2008) and in various additional validation studies (see Nussbeck \& Jackson, 2016, for an overview). The internal consistencies were high and the construct and criterion validity were satisfactory. The examination of the test-retest reliability also revealed that the questionnaire is sensitive to change. Moreover, the factorial invariance across gender could be shown in the validation study by Bodenmann (2008).

Relationship satisfaction. Relationship satisfaction was assessed by one item ("In general, how satisfied are you with your relationship?") from the Partnership Questionnaire (PFB; Hahlweg, 1996). The item was rated on a 6-point scale $(1=$ not at all satisfied to $6=$ very satisfied). Internal consistency could not be examined due to the one-item format of this measure, but former studies showed a high intercorrelation $(>.80)$ between this single item and the 30-item version of the PFB (Hahlweg, 1996). Relationship satisfaction assessed by this item was significantly associated with the respondents' dyadic coping skills (between $r=.26$ and $r=.65$ for the DCI subscales) indicating that both are relationship-related constructs, but measured different outcomes with dyadic coping being more skills oriented and relationship satisfaction being more evaluation oriented.

\section{Statistical Analysis}

In order to account for the dependency of the dyadic data and considering simultaneous change in the measures of both partners, we conducted baseline latent change score models for two factors (see McArdle, 2009). We used a multigroup modeling approach to consider differential changes in the outcome measures in the four experimental groups. Due to the relatively small sample size as compared to the complexity of the models, we ran the analyses separately for each of the four outcome measures (relationship satisfaction, own stress communication, partner's dyadic coping, evaluation of dyadic coping).

We used a stepwise model-building process. To test the general efficacy of CCET, we first built a model presuming no change with respect to the mean structure of the outcome variables (e.g., increase or decrease over time) across all four groups (Model 1a). If Model 1a has to be rejected, this implies that there is an increase or a decrease in at least some of the groups over time. Second, we built a model indicating no (zero) change on the outcome variables in the wait-list control group whereas the change in all three intervention groups was estimated to be identical (identical means and variances; Model 1b). If this model fits the data better than Model 1a, the change pattern of intervention groups differs from the no-change condition in the wait-list control group indicating that the CCET has an effect on the four outcomes; inspecting the change scores in the CCET groups will reveal if there is an increase or decrease (paradoxical effect) over time. To test the effects of hours of professional contact on treatment efficacy, we used a stepwise modeling approach using the data of the standard CCET (15 hr) and compact CCET (12 hr) groups only: In a first model, intercepts were set to 0 and mean change scores were restricted to be equal across groups implying that the two treatment formats do not differ significantly (Model 2a). If this model has to be rejected, a model with change scores restricted to be equal but with free covariances and variances (Model 2b) has to be estimated. If Model 2a or 2b fit the data, there is no differential change over time, and hence, the two formats of CCET are comparably effective. That is, the difference in hours of professional contact did not have a significant impact on treatment outcomes. To test the effects of mode of delivery on treatment efficacy, we used the same stepwise modeling approach as explained above, but comparing the data of the compact CCET (face to face only) and the short CCET (self-directed DVD and face to face) groups (Models $3 a$ and $3 b$ ). If Model $3 a$ or $3 b$ fit the data, there is no differential change over time, and thus, the mode of delivery did not affect the treatment efficacy. Likewise, the similar analytic approach was applied to compare the standard CCET and the short CCET (Model 4a, 4b). Effect sizes were calculated by dividing unstandardized change scores by the standard deviation of the variable at T1 (see Morris \& DeShon, 2002).

All analyses were run using Mplus 7.2 (Muthén \& Muthén, 1998-2015). Following recommendations of Shrout and Bolger (2002), the full information maximum likelihood estimation procedure was used to estimate model parameters and corresponding standard errors. The use of the full information estimator is warranted as we found a missing at random mechanism for very few 
missing data. Comparison of model fit is assessed relying on standard evaluations of chi-square, comparative fit index (CFI), root-mean-square error of approximation, and Akaike information criterion scores (Schermelleh-Engel, Moosbrugger, \& Müller, 2003).

\section{Results}

\section{Descriptive Analyses}

Correlations among all target variables at preassessment are listed in Table 1. Means and standard deviations for target variables at all assessments across study groups are shown in Table 2. Overall, participants reported relatively high relationship satisfaction at $\mathrm{T} 1$ (all means were higher than 4.49 on a 6-point Likert scale) and they showed high baseline means of dyadic coping skills (most of them were higher than 3.30 on a 5-point Likert scale). According to the test manual of the DCI (Bodenmann, 2008), dyadic coping skills of this sample should be considered as between average and above average relative to the validation sample ( $N=2,399$ Swiss couples). There were no significant differences within gender on relevant demographic characteristics or outcome variables at preassessment between the four groups with one exception: Women's own stress communication was significantly lower in the short CCET group than in the wait-list control group at preassessment, $F(4,143)=2.87, p=.038$.

\section{Efficacy of CCET in Dual Well-Earning Couples}

Comparing the goodness-of-fit coefficients of Models 1a and 1b allowed identifying if there were differences in change over time with respect to the outcomes between the three intervention groups and the wait-list control group. Overall, Model 1a, which implied no differences in change over time between the intervention groups and the wait-list control group, did not fit the data for all outcomes (see Table 3). Yet, sample size is comparably low for these kinds of complex models impairing the power of the chisquare test. Additionally, we found that Model 1b assuming differences between the three intervention groups and the wait-list control group fitted the data better than Model 1a. That is, all chi-square difference tests were in favor of Model $1 \mathrm{~b}$ compared to Model 1a: relationship satisfaction, $\Delta \chi^{2}(\Delta d f=12)=23.67, p=$ .02; own stress communication, $\Delta \chi^{2}(\Delta d f=12)=22.22, p=.04$;

Table 1

Correlations Among Target Variables at Preassessment Over All Groups

\begin{tabular}{llccc}
\hline \multirow{2}{*}{\multicolumn{1}{c}{ Variable }} & \multicolumn{4}{c}{ Bivariate correlations (total sample) } \\
\cline { 2 - 5 } & 1 & 2 & 3 & 4 \\
\hline 1. Own stress communication & $.19^{*}$ & $.46^{* * * *}$ & $.39^{* * * *}$ & $.29^{* * * *}$ \\
2. Partner's dyadic coping & $.29^{* * * *}$ & $.30^{* * * *}$ & $.81^{* * * *}$ & $.64^{* * * *}$ \\
3. Evaluation of coping & $.33^{* * * *}$ & $.70^{* * * *}$ & $.27^{* * * *}$ & $.65^{* * * * *}$ \\
4. Relationship satisfaction & $.26^{* * *}$ & $.47^{* * * *}$ & $.56^{* * * *}$ & $.44^{* * * *}$ \\
\hline
\end{tabular}

Note. Correlations above the diagonal are women's, under the diagonal are men's. Correlations between women and men are displayed along the diagonal.

${ }^{*} p<.05 .{ }^{* * *} p<.01 .{ }^{* * * *} p<.001$ (two-tailed). partner's dyadic coping, $\Delta \chi^{2}(\Delta d f=12)=22.01, p=.04$; and evaluation of dyadic coping, $\left.\Delta \chi^{2}(\Delta d f=12)=26.73, p=.01\right)$. Moreover, absolute fit indices for Model $1 \mathrm{~b}$ for partner's dyadic coping and evaluation of dyadic coping were good $\left(\chi^{2}=55.79\right.$, $p=.08$, and $\chi^{2}=58.40, p=.05$, respectively).

Specifically, relative to the wait-list control group, we found positive change scores (except for one score: men's report of change in partner's dyadic coping from T1 to T2) for all four dependent variables in women and men (see Table 4). However, only some of the change scores were significant, with evaluation of dyadic coping showing the strongest effects compared to the other outcomes. Likewise, the majority of the effects did not remain significant at the 6-month follow-up and all of them were minor in size. Besides the positive difference as compared to the control group, there was no simple pattern of change over time. Keeping in mind the relatively small sample sizes, the significant differences in changes in the intervention groups as compared to the wait-list control group justify to presume an effect of the interventions with respect to all four outcomes. In the remainder, we tested if there was differential change over time for meaningful pair wise group comparisons.

\section{Effects of Hours of Professional Face-to-Face Contact and Mode of Delivery}

First, we tested whether the change in outcomes differed between the standard CCET and the compact CCET. Table 3 shows that Model 2a did not fit the data but Model $2 \mathrm{~b}$ provided a good fit in terms of chi-square and CFI for all outcomes. Hence, the standard and the compact CCET did not exert differential impacts on the average change over time, yet there were differences with respect to the variability (and covariances) of change across the two groups for all outcomes.

Next, we tested whether the change in outcomes differed between the compact CCET and the short CCET. As depicted in Table 3, Model 3a had to be rejected (except for partner's dyadic coping as outcome) but Model $3 \mathrm{~b}$ fitted the data well. Again, we found no differences with respect to the average change across the compact and short CCET, but differences with respect to the variability and covariability of change.

Last, we examined whether the change in outcomes differed between the standard CCET and the short CCET where both factors (hours of professional contact and mode of delivery) varied between the groups. Model $4 \mathrm{a}$ did not fit the data, but Model $4 \mathrm{~b}$ provided an excellent fit for all outcomes indicating that the compact and the short CCET did not significantly differ in the average change scores, albeit in the covariances and variances (see Table 3). We can thus assume that the standard CCET did not exceed the efficacy of the short CCET on average, although it contains more hours of professional contact than the short format and the psychoeducation was provided face to face, while a DVD was used for psychoeducation in the short CCET.

\section{Discussion}

In this RCT, we evaluated the effect of an evidence-based CRE program, the Couples Coping Enhancement Training (CCET; Bodenmann \& Shantinath, 2004), on relationship satisfaction and dyadic coping skills in dual well-earning couples, and examined 
Table 2

Means and Standard Deviations for Target Variables at All Assessments Across Study Groups

\begin{tabular}{|c|c|c|c|c|c|c|c|c|}
\hline \multirow[b]{3}{*}{ Target variable } & \multicolumn{8}{|c|}{ Wait-list control group } \\
\hline & \multicolumn{2}{|c|}{$\mathrm{T} 1$} & \multicolumn{2}{|c|}{$\mathrm{T} 2$} & \multicolumn{2}{|c|}{$\mathrm{T} 3$} & \multicolumn{2}{|c|}{$\mathrm{T} 4$} \\
\hline & Women & Men & Women & Men & Women & Men & Women & Men \\
\hline Own stress communication & $3.81(.82)$ & $3.18(.84)$ & $3.82(.75)$ & $3.16(.86)$ & $3.86(.61)$ & $3.27(.79)$ & $3.65(.77)$ & $3.07(79)$ \\
\hline Partner's dyadic coping & $3.76(.74)$ & $3.97(.62)$ & $3.83(.75)$ & $3.86(.53)$ & $3.89(.72)$ & $3.80(.63)$ & $3.78(.82)$ & $3.92(.56)$ \\
\hline Evaluation of coping & $3.40(1.06)$ & $3.78(.73)$ & $3.57(1.05)$ & $3.67(.78)$ & $3.70(.93)$ & $3.72(.67)$ & $3.66(1.18)$ & $3.59(.83)$ \\
\hline \multirow[t]{2}{*}{ Relationship satisfaction } & $5.10(1.08)$ & $4.83(.97)$ & $5.18(.93)$ & $4.80(.96)$ & $5.08(1.03)$ & $5.03(1.03)$ & $5.11(1.16)$ & $5.03(1.03)$ \\
\hline & \multicolumn{8}{|c|}{ Short CCET } \\
\hline Own stress communication & $3.34(.69)$ & $3.12(.67)$ & $3.44(.62)$ & $3.10(.72)$ & $3.49(.75)$ & $3.34(.79)$ & $3.45(.74)$ & $3.30(.70)$ \\
\hline Partner's dyadic coping & $3.51(.80)$ & $3.63(.77)$ & $3.62(.70)$ & $3.80(.65)$ & $3.61(.73)$ & $3.82(.75)$ & $3.41(.85)$ & $3.75(.71)$ \\
\hline Evaluation of coping & $3.28(1.04)$ & $3.44(.99)$ & $3.63(.85)$ & $3.46(.93)$ & $3.56(.92)$ & $3.73(.89)$ & $3.18(.98)$ & $3.47(.99)$ \\
\hline \multirow[t]{2}{*}{ Relationship satisfaction } & $4.79(1.17)$ & $4.68(1.44)$ & $4.82(1.10)$ & $4.95(1.10)$ & $4.87(1.11)$ & $4.86(1.18)$ & $4.51(1.62)$ & $4.79(1.21)$ \\
\hline & \multicolumn{8}{|c|}{ Compact CCET } \\
\hline Own stress communication & $3.46(.80)$ & $2.82(.81)$ & $3.73(.72)$ & $2.88(.89)$ & $3.85(.80)$ & $2.95(.74)$ & $3.76(.67)$ & $2.90(.75)$ \\
\hline Partner's dyadic coping & $3.55(.80)$ & $3.67(.67)$ & $3.66(.73)$ & $3.71(.67)$ & $3.65(.77)$ & $3.62(.80)$ & $3.77(.77)$ & $3.69(.72)$ \\
\hline Evaluation of coping & $3.24(1.10)$ & $3.33(.90)$ & $3.41(.86)$ & $3.53(.93)$ & $3.46(.93)$ & $3.45(1.03)$ & $3.53(.96)$ & $3.54(.94)$ \\
\hline \multirow[t]{2}{*}{ Relationship satisfaction } & $4.72(1.09)$ & $4.49(1.26)$ & $4.86(.98)$ & $4.76(1.03)$ & $4.94(1.01)$ & $4.78(1.21)$ & $4.95(.88)$ & $4.78(.93)$ \\
\hline & \multicolumn{8}{|c|}{ Standard CCET } \\
\hline Own stress communication & $3.43(.75)$ & $3.06(.60)$ & $3.38(.83)$ & $3.07(.64)$ & $3.56(.71)$ & $3.16(.53)$ & $3.36(.81)$ & $3.23(.72)$ \\
\hline Partner's dyadic coping & $3.64(.61)$ & $3.76(.60)$ & $3.66(.71)$ & $3.96(.52)$ & $3.61(.63)$ & $3.84(.47)$ & $3.54(.68)$ & $3.72(.55)$ \\
\hline Evaluation of coping & $3.32(.84)$ & $3.42(.79)$ & $3.43(1.03)$ & $3.75(.54)$ & $3.45(.86)$ & $3.74(.56)$ & $3.22(1.16)$ & $3.62(.65)$ \\
\hline Relationship satisfaction & $4.69(1.07)$ & $5.00(.88)$ & $4.89(1.03)$ & $5.03(.92)$ & 4.79 (1.04) & $4.97(1.04)$ & $4.63(1.37)$ & $4.74(.95)$ \\
\hline
\end{tabular}

Note. $\quad \mathrm{CCET}=$ Couples Coping Enhancement Training; $\mathrm{T} 1=$ preassessment; $\mathrm{T} 2=$ postassessment; $\mathrm{T} 3=3$-month follow-up; $\mathrm{T} 4=6$-month follow-up

effects of hours of professional face-to-face contact and mode of delivery of the psychoeducational part (i.e., offered personally vs. by self-directed learning) on its efficacy. Four main results merit discussion: (1) CCET increased the couples' relationship satisfac- tion and dyadic coping skills relative to the wait-list control group, albeit the effects were small and most of them were no longer found at the follow-ups. (2) The standard format of the CCET was not more effective than the compact CCET, implying that a re-

Table 3

Model Fits for Testing Differences in Efficacy Between the Study Groups

\begin{tabular}{|c|c|c|c|c|c|c|c|c|c|c|c|c|c|c|c|c|}
\hline \multirow[b]{2}{*}{ Variable } & \multicolumn{4}{|c|}{$\begin{array}{l}\text { Model 1a: zero change } \\
\quad(d f=54)\end{array}$} & \multicolumn{4}{|c|}{$\begin{array}{l}\text { Model 1b: intervention change } \\
\qquad(d f=42)\end{array}$} & \multicolumn{4}{|c|}{$\begin{array}{l}\text { Model 2a: no effect of } \\
\text { professional contact }(d f=44)\end{array}$} & \multicolumn{4}{|c|}{$\begin{array}{l}\text { Model 2b: no effect of } \\
\text { professional contact }(d f=8)\end{array}$} \\
\hline & RS & OSC & DCP & $\overline{\mathrm{EDC}}$ & $\mathrm{RS}$ & OSC & DCP & EDC & RS & OSC & DCP & EDC & $\mathrm{RS}$ & OSC & DCP & EDC \\
\hline$\chi^{2}$ & 114.35 & 82.15 & 77.80 & 85.13 & 90.68 & 59.93 & 55.79 & 58.40 & 67.28 & 72.75 & 78.14 & 92.91 & 8.04 & 14.56 & 12.95 & 7.74 \\
\hline & $<.01$ & $<.01$ & .02 & $<.01$ & $<.01$ & .04 & .08 & .05 & .01 & $<.01$ & $<.01$ & $<.01$ & .43 & .07 & .11 & .46 \\
\hline CFI & .93 & .95 & .98 & .96 & .94 & .97 & .99 & .98 & .97 & .95 & .97 & .93 & 1.00 & .99 & .96 & 1.00 \\
\hline RMSEA & .17 & .12 & .11 & .12 & .17 & .10 & .09 & .10 & .12 & .13 & .14 & .17 & .01 & .14 & .13 & .00 \\
\hline \multirow[t]{2}{*}{ AIC } & 2883 & 2261 & 1626 & 2526 & 2884 & 2262 & 1628 & 2523 & 2856 & 2271 & 1646 & 2553 & 2869 & 2285 & 1653 & 2540 \\
\hline & \multicolumn{4}{|c|}{$\begin{array}{l}\text { Model 3a: no effect of mode of } \\
\text { delivery }(d f=44)\end{array}$} & \multicolumn{4}{|c|}{$\begin{array}{l}\text { Model 3b: no effect of mode of } \\
\text { delivery }(d f=8)\end{array}$} & \multicolumn{4}{|c|}{$\begin{array}{l}\text { Model 4a: no effect of } \\
\text { professional contact/mode of } \\
\text { delivery combined }(d f=44)\end{array}$} & \multicolumn{4}{|c|}{$\begin{array}{l}\text { Model } 4 \mathrm{~b} \text { : no effect of } \\
\text { professional contact } / \text { mode of } \\
\text { delivery combined }(d f=8)\end{array}$} \\
\hline$\chi^{2}$ & 100.15 & 74.22 & 49.22 & 63.70 & 3.67 & 14.02 & 9.13 & 12.80 & 88.03 & 59.1 & 78.52 & 61.86 & 9.60 & 2.77 & 5.00 & 8.24 \\
\hline . & $<.01$ & $<.01$ & .28 & .03 & .88 & .08 & .3 & .12 & $<.01$ & .06 & $<.01$ & .04 & .29 & .95 & .76 & .41 \\
\hline CFI & .93 & .95 & 1.00 & .97 & 1.00 & .99 & 1.00 & .99 & .95 & .97 & .97 & .98 & 1.00 & 1.00 & 1.00 & 1.00 \\
\hline RMSEA & .18 & .13 & .06 & .11 & .00 & .14 & .06 & .12 & .16 & .09 & .14 & .10 & .07 & .00 & .07 & .03 \\
\hline AIC & 2889 & 2273 & 1617 & 2524 & 2865 & 2285 & 1649 & 2545 & 2877 & 2258 & 1646 & 2522 & 2870 & 2273 & 1644 & 2540 \\
\hline
\end{tabular}

Note. Model 1a assumes no differences between groups; Model $1 \mathrm{~b}$ assumes significant change in intervention groups; Model 2a assumes no differences in changes and (co-)variances between standard and compact Couples Coping Enhancement Training (CCET); Model 2b assumes no differences in changes between standard and compact CCET, but (co-)variances are freely estimated; Model 3a assumes no differences in changes and (co-)variances between compact and short CCET; Model 3b assumes no differences in changes between compact and short CCET, but (co-)variances are freely estimated; Model 4a assumes no differences in changes and (co-)variances between standard and short CCET; Model 4b assumes no differences in changes between standard and short CCET, but (co-)variances are freely estimated. $\mathrm{CFI}=$ comparative fit index; RMSEA = root-mean-square error of approximation; $\mathrm{AIC}=\mathrm{Akaike}$ information criterion; $\mathrm{RS}=$ relationship satisfaction; OSC = own stress communication; DCP = partner's dyadic coping; EDC = evaluation of dyadic coping. 
Table 4

Unstandardized Change Scores and Effect Sizes Over All Intervention Groups (Model 1b)

\begin{tabular}{|c|c|c|c|c|c|c|c|c|}
\hline \multirow[b]{2}{*}{ Group } & \multicolumn{4}{|c|}{ Change scores } & \multicolumn{4}{|c|}{ Effect sizes } \\
\hline & RS & OSC & DCP & EDC & RS & OSC & DCP & EDC \\
\hline \multicolumn{9}{|l|}{ Women } \\
\hline $\mathrm{C}_{\mathrm{T} 2-\mathrm{T} 1}$ & $.07(.43)$ & $.02(.80)$ & $.06(.23)$ & $.20(.02)$ & .07 & .03 & .08 & .20 \\
\hline $\mathrm{C}_{\mathrm{T} 3-\mathrm{T} 1}$ & $.06(.56)$ & $.16(.01)$ & $.04(.45)$ & $.17(.03)$ & .06 & .20 & .05 & .17 \\
\hline $\mathrm{C}_{\mathrm{T}}$ & $-.06(.59)$ & $.05(.40)$ & .02 (.69) & $.09(.38)$ & -.06 & .06 & .03 & .09 \\
\hline \multicolumn{9}{|l|}{ Men } \\
\hline $\mathrm{C}_{\mathrm{T} 2-\mathrm{T} 1}$ & $.25(.10)$ & $-.04(.62)$ & $.14(<.01)$ & $.20(.01)$ & .28 & -.05 & .20 & .22 \\
\hline $\mathrm{C}_{\mathrm{T}}$ & $.22(.04)$ & $.10(.14)$ & $.07(.20)$ & $.23(.01)$ & .24 & .13 & .10 & .26 \\
\hline $\mathrm{C}_{\mathrm{T} 4-\mathrm{T} 1}$ & $.04(.66)$ & $.16(.03)$ & $.04(.48)$ & $.17(.04)$ & .04 & .21 & .06 & .19 \\
\hline
\end{tabular}

Note. Unstandardized change scores over all intervention groups are shown (two-tailed $p$ values in parentheses). Significant values are in boldface type $(p<.05)$. Effect sizes are shown for each intervention group. Effect sizes were calculated by dividing unstandardized change scores by the standard deviation of the variable at T1. $\mathrm{RS}=$ relationship satisfaction; OSC = own stress communication; $\mathrm{DCP}=$ partner's dyadic coping; $\mathrm{EDC}=$ evaluation of dyadic coping; $\mathrm{C}_{\mathrm{T} 2-\mathrm{T} 1}=$ change at postassessment; $\mathrm{C}_{\mathrm{T} 3-\mathrm{T} 1}=$ change at 3-month follow-up; $\mathrm{C}_{\mathrm{T} 4-\mathrm{T} 1}=$ change at 6-month follow-up.

duction of $3 \mathrm{hr}$ of professional contact (from 15 to $12 \mathrm{hr}$ face to face) did not decrease the treatment's efficacy. (3) There was no meaningful difference in the target outcomes between the compact and the short CCET groups, indicating that the self-learning DVD successfully replaced the psychoeducational part delivered by a provider in the compact CCET. (4) Even the standard CCET with more hours of professional contact that was all provided face to face did not outperform the short CCET containing the DVD.

Taken together, we found that CCET produced beneficial effects over all treatment formats relative to the wait-list control group, although many changes did not yield significance. Most of the effects were found on couples' subjective evaluation of dyadic coping as the targeted outcome, which persisted through the 3-month follow-up in women and through the 6-month follow-up in men. Hence, rather than specific dyadic coping behavior skills, the evaluation of the quality of the partner's dyadic coping behavior as a whole appears more amenable to the treatment. It is conceivable that this outcome is best targeted by the program or the improvements in this outcome are better and faster perceptible for partners compared to the other outcomes. However, it is also plausible that engaging in the CCET mostly fostered couples' expectations that the perceived quality of the partner's support should increase following the program, more so than specific behavior skills per se. Behavior skills might also be more difficult to evaluate accurately with regard to change in couples performing already quite well. Moreover, the couples received much psychoeducation about the positive impact of good partner support on the intimate relationship and the enhanced knowledge in this regard could also lead to a more sensitive consideration of the evaluation outcome compared to the other outcomes.

However, all effects were modest in size (irrespective of outcome variable or gender). This is in accordance with effect sizes in prevention-oriented, universal CRE programs at short-term followups reported in prior meta-analyses (Halford \& Bodenmann, 2013; Hawkins et al., 2008). The small intervention effects found in this study can probably be explained by the fact that our sample are relatively high functioning couples. As dual well-earning couples often have many resources (stable and high income, high selfrealization, high living standard, etc.) they may be functionally too well-off to perceive benefits of the intervention over 6 months. A longer-term follow-up is needed to test whether the program is preventive in the long run.

Remarkably, treatment effects on men's relationship satisfaction were more favorable compared to women's reports. This is at odds with several prior studies suggesting that women tend to benefit more from CRE than men (Halford et al., 2010; Hawkins et al., 2008; Ledermann et al., 2007). It has to be assumed that our study sample (dual well-earning couples) is more homogenous in terms of females' and males' perceived everyday stress levels. It is likely that under these circumstances men tend to benefit better from a stress-preventive CRE program aimed at fostering couple's dyadic skills to cope with stress.

The three formats of CCET were largely equivalent in their effects indicating no differential impact depending on hours of professional contact and mode of delivery of psychoeducation. Notably, the combination of a psychoeducational self-learning DVD and just $8 \mathrm{hr}$ of face-to face training showed similar effects as the standard and the compact format of the CCET (15 and $12 \mathrm{hr}$ face to face). In the interpretation of the data, it must be kept in mind that the feature of the short CCET was not related to the skills training (same length and quality as the other two formats) but to the psychoeducational part and the mode of its delivery (personal vs. self-directed via DVD). However, even though training and supervision of couples in exercises were held analogously across the three intervention groups, the different forms of delivering meant differing time intensity of skills training, too. That is, in the short format all exercises of the skills training happened one after the other with only short evaluation phases in between. Couples were thus more immediately confronted with skills training and had no warming-up phase in the short CCET, whereas there was a short warming-up in the evening prior to the skills training in the compact CCET and more intense warming-up skills training with in-between psychoeducation in the standard format. Conversely, couples from the short CCET group may have had more time to reflect on the psychoeducational messages compared to the other two groups since they received the DVD 2 weeks prior to the skills training. 
Although we did not find differential effects for the three treatment formats, we found differences with respect to the variances and associations of the target variables across the three treatment groups. That is, we found differing interindividual differences and also different correlations with respect to the initial levels and the change scores of the outcomes. However, we could not identify a readily interpretable pattern of differences across the three groups which leads us to conclude that in future studies researchers should also collect information about possible moderators of treatment efficacy.

\section{Practical and Clinical Implications}

The present results have three important implications: (a) extensive warming up of the couples is not needed; (b) psychoeducation is less substantial than skills training and the duration of this part of the program appears less important; (c) the delivery of psychoeducation, that is, face to face by a provider or by means of self-directed learning, does not matter. In other words, we found evidence that psychoeducation delivered by DVD is as effective as in person and that psychoeducation may be less important than skills training to achieve benefits in CRE. In this RCT, skills training was not moderated in its duration or quality as we believe that this element is particularly important in CRE, provided in a workshop format. The DVD replaced the psychoeducational part of the CCET exclusively, thereby leading to lower time dosage with regard to theory and discussion in the plenum, but not regarding skills training.

These findings are in line with prior research that improvements in relationship outcomes were higher when CRE involved 10-12 face-to-face hours, but there were no gains added by additional face-to-face contact (Stanley, Amato, Johnson, \& Markman, 2006). It appears that there is an optimum for cost-effectiveness in CRE. In the case of CCET, the short and even the compact format is more economical (i.e., lower cost for providers and room expenses and thus lower price for couples) than the standard format, yet retaining good client outcome. Moreover, the required time commitment for participants is lower, which might be of particular importance to couples where both partners work. These couples usually deal with many stressors in the workplace and within the relationship given that the reciprocal spillover of stress between these two domains is established empirically (e.g., Schulz et al., 2004). Furthermore, our results correspond with the meta-analytic finding that blended programs (combining self-directed learning plus face-to-face elements) are auspicious in CRE (McAllister et al., 2012). Dual-earner couples may particularly benefit from blended programs to the extent that they require less time and allow more flexible use in comparison to traditional (face to face only) approaches (Halford et al., 2010). In general, these numerous advantages may lower barriers couples usually face (and probably dual earner couples in particular) when attending a longer, faceto-face relationship distress prevention program. CRE including flexible delivery programs can be undertaken at a time and a place that suit couples and may thus enhance access to dual-earner couples who might otherwise not participate in a program. This may be the reason why self-directed approaches are increasingly proposed in the context of CRE (Bodenmann et al., 2014; Braithwaite \& Fincham, 2014; Halford et al., 2004). By the same token, a drawback of only self-directed programs may be the lack of individualized and personal support couples receive, as opposed to in person delivery (e.g., Braithwaite \& Fincham, 2009, 2011). Therefore, blended programs strive to combine the advantages of self-directed and face-to-face elements to maximize the efficacy of CRE.

\section{Study Limitations}

Some limitations may have compromised the results of our research. The most important among them is that all study variables were assessed by self-report measures entailing the risk of inflated effects because of shared method variance. Second, we acknowledge the methodological limitation inherent to measure relationship satisfaction by one item. Also, the present research focused on relationship variables, although work satisfaction would be a further intriguing outcome to investigate with dual well-earning couples. Third, as we used a wait-list control group it was not possible to show specific effects of CCET. The mere fact that the couples committed to do something for their relationship and had conversations with their partners might have positive effects independent of the content of CCET. Fourth, the difference in hours of professional contact between the standard and the compact CCET is small, but notwithstanding of notable relevance in practice (concerning cost and time restrictions for couples, for instance). Fifth, although our sample size was similar or larger than many other published evaluations of CRE programs, with approximately 40 couples per condition the power of this study to detect differential effects between the treatments was limited. Due to the differing associations of our study variables, power analysis and a priori sample size calculations differ to some extent. We therefore refer to Prindle and McArdle (2012), who recommended collecting data from 270 observational units for a roughly comparable multigroup dual change score model with small effect sizes (baseline latent change score model) to obtain a power of .80 for the chi-square test. Sixth, our participants were dual well-earning couples from a universal prevention sample (no increased risk or relationship distress at baseline). Our target sample was better educated and had higher income relative to average Swiss couples and they reported relatively high dyadic coping skills and relationship satisfaction at baseline. Further research is needed to unveil whether the current findings are generalizable to less privileged and more relationally or financially distressed couples. On the other hand, given dual-earner couples may perceive above-average everyday stress and have particularly little time to invest in CRE, our findings are potentially shaped by the specific nature of our study sample. Last, we had a relatively short follow-up of 6 months. A longer-term follow-up is crucially important to test whether the program is preventive in the long run.

\section{Conclusion}

In summary, this study makes a contribution to the emerging research about relationship education for dual well-earning couples. Since they face demands from the work and the relationship domain simultaneously, it is a promising finding that they can strengthen their relationship with a relatively short time investment. Blended CRE could enhance the potential adoption of programs particularly in this target group by minimizing required 
time, reducing cost of delivery, and increasing convenience of access for couples. We believe that coping-oriented CRE is a potent means to strengthen dual well-earning couples' coping skills in order to be prepared for times of high stress.

\section{References}

Bodenmann, G. (1995). A systemic-transactional conceptualization of stress and coping in couples. Swiss Journal of Psychology, 54, 34-49.

Bodenmann, G. (2008). Dyadisches Coping Inventar: DCI [Dyadic Coping Inventory: DCI]. Bern, Switzerland: Huber.

Bodenmann, G., Hilpert, P., Nussbeck, F. W., \& Bradbury, T. N. (2014). Enhancement of couples' communication and dyadic coping by a selfdirected approach: A randomized controlled trial. Journal of Consulting and Clinical Psychology, 82, 580-591. http://dx.doi.org/10.1037/ a0036356

Bodenmann, G., Meuwly, N., Bradbury, T. N., Gmelch, S., \& Ledermann, T. (2010). Stress, anger, and verbal aggression in intimate relationships: Moderating effects of individual and dyadic coping. Journal of Social and Personal Relationships, 27, 408-424. http://dx.doi.org/10.1177/ 0265407510361616

Bodenmann, G., Schaer, M., \& Gmelch, S. (2008). Paarlife-Glücklich zu zweit trotz Alltagsstress [CCET-DVD-Happy together despite daily hassles]. Zurich, Switzerland: University of Zurich.

Bodenmann, G., \& Shantinath, S. D. (2004). The Couples Coping Enhancement Training (CCET): A new approach to prevention of marital distress based upon stress and coping. Family Relations, 53, 477-484. http://dx.doi.org/10.1111/j.0197-6664.2004.00056.x

Braithwaite, S. R., \& Fincham, F. D. (2007). ePREP: Computer based prevention of relationship dysfunction, depression and anxiety. Journal of Social and Clinical Psychology, 26, 609-622. http://dx.doi.org/10 $.1521 /$ jscp.2007.26.5.609

Braithwaite, S. R., \& Fincham, F. D. (2009). A randomized clinical trial of a computer based preventive intervention: Replication and extension of ePREP. Journal of Family Psychology, 23, 32-38. http://dx.doi.org/10 $.1037 / \mathrm{a} 0014061$

Braithwaite, S. R., \& Fincham, F. D. (2011). Computer-based dissemination: A randomized clinical trial of ePREP using the actor partner interdependence model. Behaviour Research and Therapy, 49, 126-131. http://dx.doi.org/10.1016/j.brat.2010.11.002

Braithwaite, S. R., \& Fincham, F. D. (2014). Computer-based prevention of intimate partner violence in marriage. Behaviour Research and Therapy, 54, 12-21. http://dx.doi.org/10.1016/j.brat.2013.12.006

Brock, R. L., \& Lawrence, E. (2008). A longitudinal investigation of stress spillover in marriage: Does spousal support adequacy buffer the effects? Journal of Family Psychology, 22, 11-20. http://dx.doi.org/10.1037/ 0893-3200.22.1.11

Duncan, S. F., Steed, A., \& Needham, C. M. (2009). A comparison evaluation study of web-based and traditional marriage and relationship education. Journal of Couple \& Relationship Therapy, 8, 162-180. http://dx.doi.org/10.1080/15332690902813836

Edwards, J. R., \& Rothbard, N. P. (2000). Mechanisms linking work and family: Clarifying the relationship between work and family constructs. Academy of Management Review, 25, 178-199.

Falconier, M. K., \& Epstein, N. B. (2011). Female-demand/male-withdraw communication in Argentinian couples: A mediating factor between economic strain and relationship distress. Personal Relationships, 18, 586-603. http://dx.doi.org/10.1111/j.1475-6811.2010.01326.x

Falconier, M. K., Jackson, J. B., Hilpert, P., \& Bodenmann, G. (2015). Dyadic coping and relationship satisfaction: A meta-analysis. Clinical Psychology Review, 42, 28-46. http://dx.doi.org/10.1016/j.cpr.2015.07 .002

Frone, M. R., Russell, M., \& Cooper, M. L. (1992). Antecedents and outcomes of work-family conflict: Testing a model of the work-family interface. Journal of Applied Psychology, 77, 65-78. http://dx.doi.org/ 10.1037/0021-9010.77.1.65

Greenhaus, J. H., \& Powell, G. N. (2006). When work and family are allies: A theory of work-family enrichment. Academy of Management Review, 31, 72-92. http://dx.doi.org/10.5465/AMR.2006.19379625

Hahlweg, K. (1996). Partnerschaftsfragebogen (PFB) [Partnership Questionnaire]. Test manual. Göttingen, Germany: Hogrefe Tests.

Halford, W. K. (2001). Marriage and relationship education: What works and how to provide it. New York, NY: Guilford Press.

Halford, W. K., \& Bodenmann, G. (2013). Effects of relationship education on maintenance of couple relationship satisfaction. Clinical Psychology Review, 33, 512-525. http://dx.doi.org/10.1016/j.cpr.2013.02.001

Halford, W. K., Moore, E., Wilson, K. L., Farrugia, C., \& Dyer, C. (2004). Benefits of flexible delivery relationship education: An evaluation of the couple CARE program. Family Relations, 53, 469-476. http://dx.doi .org/10.1111/j.0197-6664.2004.00055.x

Halford, W. K., Sanders, M. R., \& Behrens, B. C. (2001). Can skills training prevent relationship problems in at-risk couples? Four-year effects of a behavioral relationship education program. Journal of Family Psychology, 15, 750-768. http://dx.doi.org/10.1037/0893-3200.15.4 .750

Halford, W. K., Wilson, K., Watson, B., Verner, T., Larson, J., Busby, D., \& Holman, T. (2010). Couple relationship education at home: Does skill training enhance relationship assessment and feedback? Journal of Family Psychology, 24, 188-196. http://dx.doi.org/10.1037/a0018786

Hawkins, A. J., Blanchard, V. L., Baldwin, S. A., \& Fawcett, E. B. (2008). Does marriage and relationship education work? A meta-analytic study. Journal of Consulting and Clinical Psychology, 76, 723-734. http://dx .doi.org/10.1037/a0012584

Hawkins, A. J., Stanley, S. M., Blanchard, V. L., \& Albright, M. (2012). Exploring programmatic moderators of the effectiveness of marriage and relationship education programs: A meta-analytic study. Behavior Therapy, 43, 77-87. http://dx.doi.org/10.1016/j.beth.2010.12.006

Ilies, R., Schwind, K. M., Wagner, D. T., Johnson, M. D., DeRue, D. S., \& Ilgen, D. R. (2007). When can employees have a family life? The effects of daily workload and affect on work-family conflict and social behaviors at home. Journal of Applied Psychology, 92, 1368-1379. http://dx.doi.org/10.1037/0021-9010.92.5.1368

Ledermann, T., Bodenmann, G., \& Cina, A. (2007). The efficacy of the Couples Coping Enhancement Training (CCET) in improving relationship quality. Journal of Social and Clinical Psychology, 26, 940-959. http://dx.doi.org/10.1521/jscp.2007.26.8.940

Matthews, R. A., Del Priore, R. E., Acitelli, L. K., \& Barnes-Farrell, J. L. (2006). Work-to-relationship conflict: Crossover effects in dual-earner couples. Journal of Occupational Health Psychology, 11, 228-240. http://dx.doi.org/10.1037/1076-8998.11.3.228

McAllister, S., Duncan, S. F., \& Hawkins, A. J. (2012). Examining the early evidence for self-directed marriage and relationship education: A meta-analytic study. Family Relations, 61, 742-755. http://dx.doi.org/10 $.1111 / j .1741-3729.2012 .00736 . x$

McArdle, J. J. (2009). Latent variable modeling of differences and changes with longitudinal data. Annual Review of Psychology, 60, 577-605. http://dx.doi.org/10.1146/annurev.psych.60.110707.163612

Morris, S. B., \& DeShon, R. P. (2002). Combining effect size estimates in meta-analysis with repeated measures and independent-groups designs. Psychological Methods, 7, 105-125. http://dx.doi.org/10.1037/1082989X.7.1.105

Muthén, L. K., \& Muthén, B. O. (1998-2015). Mplus user's guide (7.2th ed.). Los Angeles, CA: Muthén \& Muthén.

Neff, L. A., \& Karney, B. R. (2004). How does context affect intimate relationships? linking external stress and cognitive processes within marriage. Personality and Social Psychology Bulletin, 30, 134-148. http://dx.doi.org/10.1177/0146167203255984

Nussbeck, F. W., \& Jackson, J. B. (2016). Measuring dyadic coping across 
cultures. In M. K. Falconier, A. K. Randall, \& G. Bodenmann (Eds.), Couples coping with stress-A cross-cultural perspective (pp. 36-53). New York, NY: Routledge.

Peeters, M. C. W., Montgomery, A. J., Bakker, A. B., \& Schaufeli, W. B. (2005). Balancing work and home: How job and home demands are related to burnout. International Journal of Stress Management, 12, 43-61. http://dx.doi.org/10.1037/1072-5245.12.1.43

Petch, J. F., Halford, W. K., Creedy, D. K., \& Gamble, J. (2012). A randomized controlled trial of a couple relationship and coparenting program (Couple CARE for Parents) for high- and low-risk new parents. Journal of Consulting and Clinical Psychology, 80, 662-673. http://dx .doi.org/10.1037/a0028781

Prindle, J. J., \& McArdle, J. J. (2012). An examination of statistical power in multigroup dynamic structural equation models. Structural Equation Modeling, 19, 351-371. http://dx.doi.org/10.1080/10705511.2012 .687661

Revenson, T. A., Kayser, K., \& Bodenmann, G. (Eds.). (2005). Couples coping with stress: Emerging perspectives on dyadic coping. Washington, DC: American Psychological Association. http://dx.doi.org/10 1037/11031-000

Schermelleh-Engel, K., Moosbrugger, H., \& Müller, H. (2003). Evaluating the fit of structural equation models: Tests of significance and descriptive goodness-of-fit measures. Methods of Psychological Research, 8, 23-74.

Schulz, M. S., Cowan, P. A., Cowan, C. P., \& Brennan, R. T. (2004). Coming home upset: Gender, marital satisfaction, and the daily spillover of workday experience into couple interactions. Journal of Family Psychology, 18, 250-263. http://dx.doi.org/10.1037/0893-3200.18.1 .250

Shrout, P. E., \& Bolger, N. (2002). Mediation in experimental and nonexperimental studies: New procedures and recommendations. Psychological Methods, 7, 422-445. http://dx.doi.org/10.1037/1082-989X.7.4 422

Sonnentag, S. (2003). Recovery, work engagement, and proactive behavior: A new look at the interface between nonwork and work. Journal of Applied Psychology, 88, 518-528. http://dx.doi.org/10.1037/0021-9010 88.3.518

Stanley, S. M., Amato, P. R., Johnson, C. A., \& Markman, H. J. (2006). Premarital education, marital quality, and marital stability: Findings from a large, random household survey. Journal of Family Psychology, 20, 117-126. http://dx.doi.org/10.1037/0893-3200.20.1.117

Story, L. B., \& Repetti, R. (2006). Daily occupational stressors and marital behavior. Journal of Family Psychology, 20, 690-700. http://dx.doi.org/ 10.1037/0893-3200.20.4.690

Wilson, K. L., \& Halford, W. K. (2008). Processes of change in selfdirected couple relationship education. Family Relations, 57, 625-635. http://dx.doi.org/10.1111/j.1741-3729.2008.00529.x 